\title{
Concomitant wastewater treatment with lipid and carotenoid production by the oleaginous yeast Rhodosporidium toruloides grown on brewery effluent enriched with sugarcane molasses and urea
}

\author{
Carla Dias $^{\mathrm{a}}$, Alberto Reis ${ }^{\mathrm{a}}$, José A.L. Santos ${ }^{\mathrm{b}, \mathrm{c}}$, Teresa Lopes da Silva ${ }^{\mathrm{a}, *}$ \\ ${ }^{a}$ Unidade de Bioenergia, e Biorrefinarias, Estrada do Paço do Lumiar 22, 1469-038 Lisboa, Portugal \\ ${ }^{\mathrm{b}}$ Departamento de Bioengenharia, Instituto Superior Técnico, Universidade de Lisboa, Avenida Rovisco Pais, 1049-001 Lisboa, Portugal \\ ${ }^{\mathrm{c}}$ IBB, Institute for Biotechnology and Bioengineering, Avenida Rovisco Pais, 1049-001 Lisboa, Portugal
}

\section{A R T I C L E I N F O}

\section{Keywords:}

Rhodosporidium toruloides

Brewery wastewater

Sugarcane molasses

Lipids

Flow cytometry

\begin{abstract}
A B S T R A C T
In this study, secondary brewery wastewater (SBWW) supplemented with sugarcane molasses (SCM) was used for SBWW treatment with concomitant lipid and carotenoid production by the yeast Rhodosporidium toruloides NCYC 921. In order to improve the biomass production, ammonium sulfate, yeast extract and urea were tested as nitrogen sources. Urea was chosen as the best low-cost nitrogen source. A fed-batch cultivation was carried out with SBWW supplemented with $10 \mathrm{~g} \mathrm{~L}^{-1}$ of sugarcane molasses as carbon source, and $2 \mathrm{~g} \mathrm{~L}^{-1}$ of urea as nitrogen source. A maximum biomass concentration of $42.5 \mathrm{~g} \mathrm{~L}^{-1}$ was obtained at $\mathrm{t}=126.5 \mathrm{~h}$ and the maximum biomass productivity was $0.55 \mathrm{~g} \mathrm{~L}^{-1} \mathrm{~h}^{-1}$ at $\mathrm{t}=48.25 \mathrm{~h}$. The maximum lipid content was $29.9 \% \mathrm{w} / \mathrm{w}(\mathrm{DCW})$ at $\mathrm{t}=94 \mathrm{~h}$ of cultivation and the maximum carotenoid content was $0.23 \mathrm{mg} \mathrm{g}^{-1}$ at $120 \mathrm{~h}$ of cultivation. Relatively to the SBWW treatment, after the batch phase, $45.8 \%$ of total Kjeldahl nitrogen removal, $81.7 \%$ of COD removal and $100 \%$ of sugar consumption were observed. Flow cytometry analysis revealed that $27.27 \%$ of the cells had injured membrane after the inoculation. This proportion was reduced to $10.37 \%$ at the end of the cultivation, indicating that cells adapted to the growth conditions.
\end{abstract}

\section{Introduction}

In the food and beverage sectors, the brewery industry is a very important section of the economy of many countries. Currently, beer is the fifth most consumed beverage in the world [1,2]. The brewing process consumes large amounts of water and generates between 3-10 $\mathrm{L}$ of wastewater per $1 \mathrm{~L}$ of beer produced [2,3]. This represents large volumes of brewery wastewater that must be treated, usually, by municipal treatment plants, which represents an excessive amount of waste and also high costs to brewery operators [4,5]. Considering this, the need for developing more efficient methods for brewery wastewater treatment is urgent.

Nowadays, the wastewater from a brewery plant has several destinations: it can be discharged directly to a water stream (river, ocean or lake), it can be completely treated by a municipal sewer system or transferred to this system after a pretreatment in the brewery, or it can be completely treated by a wastewater treatment plant from the brewery [6]. Discharging an untreated or not completely treated effluent in waterways can cause serious pollution problems in the water bodies since this effluent still contains a large quantity of nutrients, which causes eutrophication [6-8]. Moreover, environmental legislation is being more stringent, so companies have to comply with wastewater discharge limits when discharging effluents.

Pretreatment of brewery wastewater can be performed using three different methods: physical methods where physical forces are applied to remove contaminants, which allows the suspended solids to settle or to float, removing little BOD, and should be combined with other methods; chemical methods that can be $\mathrm{pH}$ adjustment or coagulation and flocculation, where small particles can aggregate and then be removed easily by physical separation; biological methods where microorganisms convert the biodegradable organics pollutants in the wastewaters. The last method is usually the one used for pretreatment of brewery wastewater has it allows high biological oxygen demand (BOD) and chemical oxygen demand (COD) removal and requires low investment cost [6].

The common biological treatment processes used are based on the activity of a wide range of microorganisms that throughout aerobic or anaerobic processes, convert the biodegradable organic pollutants

\footnotetext{
* Corresponding author.

E-mail address: teresa.lopessilva@lneg.pt (T. Lopes da Silva).
} 